\title{
TECHNOLOGICAL AND SOCIAL RETROFIT STRATEGIES FOR THE PUBLIC RESIDENTIAL BUILDINGS OF THE SECOND POST-WAR
}

\author{
MICHELE DI SIVO $^{1}$, DANIELA LADIANA ${ }^{2}$, GIOVANNI SANTI ${ }^{1}$, and LEDIANA \\ RRJOLLI $^{1}$ \\ ${ }^{I}$ Dept of Energy, Systems, Territory, and Constructions Engineering \\ (D.E.S.T.e.C.), University of Pisa, Pisa, Italy \\ ${ }^{2}$ Dept of Architecture, University G. D'Annunzio of Chieti-Pescara, Pescara, Italy
}

\begin{abstract}
This experimental study on the renewal of post-World War II suburban areas addresses the theme of the technological retrofitting of buildings, focusing on typological features, construction techniques and, more in general, of all aspects that fail to meet the needs of contemporary living. An initial examination of Italian and international case studies helped to identify possible guidelines for the optimization of urban renewal activities. The guidelines were tested by applying them to a case study: a 1950s-era neighborhood in the city of Pisa. The study undertaken highlights the need to consistently integrate all of the activities that affect the building structures consolidations and static adjustments, improvement of energy efficiency, functional and spatial adaptation - and that work towards strengthening social integration by taking into account the specific needs of the individual. The work is implemented on individual buildings and urban areas, with the aim of improving the local identity characteristics. The suggested approach is that of a circular economy, which helps to reduce the impact on the environment, mainly through the extensive use of recycled materials. The proposed experiment thus aims to test the resilience of buildings following their seismic, energy and functional updating, including sociological and environmental psychology assessments, with particular attention to vulnerable users, in order to find solutions capable of promoting social inclusion.
\end{abstract}

Keywords: Suburbs, Urban and social renewal, Social housing, Integrated retrofitting, Seismic adaptation.

\section{URBAN RENEWAL AND SOCIAL HOUSING}

Statistics show that around $75 \%$ of the European population currently lives in urban areas, a number that is expected to increase to $80 \%$ by 2020 ; the number could exceed $90 \%$ in as many as seven Member States. Furthermore, since the mid-1950, the total area of urban areas in the EU has increased by $78 \%$, compared to a population growth of only $33 \%$. According to the UNHabitat 2016 World City Report (UN-Habitat 2016), 70\% of urban land is occupied by housing. This modality of expansion, defined by experts as the "occupation of decoupled land", is attributable to profound changes in lifestyles and to the obsolescence of housing, which is no longer capable of fitting in with new paradigms of contemporary housing (Di Sivo and Cellucci 2016), rather than to population growth. It is, therefore, apparent that urgent and critical action be taken to slow down this phenomenon. There must be a shift from the tendency towards the 
indefinite and relentless expansion of cities (Latouche 2012) to that of urban renewal, not only, of the historical town centers but also of those early suburbs that have been subsumed by the rapid expansion of recent decades (Landolfo et al. 2013).

Within this framework lies an important area of work that has been identified as a priority for intervention: the social housing built in the period after the Second World War. Built following the destruction of the war and the subsequent steady urbanization of the population, it is unthinkable that this housing can be demolished on a large scale (Giacchetta 2012) and, although it must be adapted to the changed housing standards and the new energy/environmental constraints, it may prove to be an important resource for residential policies.

The modern implications of all this is that the significant functional and technological obsolescence of these structures is also accompanied by marked and evident physical deterioration. In particular, social changes with regard to the composition of households and the age of the occupants, together with changes in energy availability and technological progress, tend to modify the uses and habits of residents (Jacobs 1961) and accelerate the process of obsolescence.

It therefore seems appropriate that research in the field of technological and environmental design aim towards determining possible approaches, methods, and tools to facilitate the optimization of urban renewal activities for these settings. This involves implementing strategies, policies, and interventions aimed at increasing urban resiliency, by adapting city systems so that, under variable conditions, these are capable of systemic adaptation and flexibility so as to render it possible to simulate behaviors and alternatives of response (Habraken 1998).

An experimental research initiative is underway at the University of Pisa, where a working group is carrying out studies and projects in a neighborhood of Pisa with the aim of coming up with a valid approach for the types of building found mainly in post-war Italian housing that characterizes the earliest suburbs of Italian cities.

\subsection{A Possible Approach}

The research began with a study of the current housing stock, making a thorough examination of the buildings - including the typological features, the construction techniques - as well as on the building stock in Italy and in Europe, upon which qualitative/quantitative assessments were made of the technological and energy deficits encountered. See Table 1.

An assessment of these experiences confirmed the necessity of taking an integrated approach that takes into account the object as a whole and makes use of all the elements available to enhance its potential (Bellomo and Pone 2011). The traditional approach of making timely interventions aimed at responding to individual problems is in fact not completely effective in terms of reformulating building features and architecture.

The aim of retrofitting is to renew the building system in question by operating both on the environmental and technological sub-system utilizing an architectural project capable of implementing, enhancing or improving (depending on current needs) the energy, structural, seismic, and functional features of the building. Retrofitting consists in the introduction of new features not included in original project phase or, in any case, not provided (Ascione and Bellomo 2012); it may involve the entire building or only certain parts of it; it may be superficial or volumetric depending on the elements involved; it may involve integrating or replacing the shell, structure or systems, or removing or adding entire volumes or parts of the building. Utilizing retrofitting strategies brings various types of issues into play that are found in operational practices of multiple technical fields such as feedback and adaptation through the application of innovative solutions, new technologies, new integrative elements or in modification of physical 
and functional characteristics and features of existing elements. Being a relatively recent approach, retrofitting is a realm that is still open to new areas and possibilities for development. Implemented mainly to achieve the improvement/updating of energy and functional features, more recently it has kept in stride with the progress of increasingly less-standardized market offerings (Di Sivo and Angelucci 2012), moving towards custom-fitting, in attempt to respond to the specific needs of users. This implies greater attention towards the final user of the "improved" product which adds not only to the technological connotations of retrofitting, but also to social ones aimed at increasing the quality of the housing.

Table 1. Project strategies extrapolated from the assessment of Italian and European case studies.

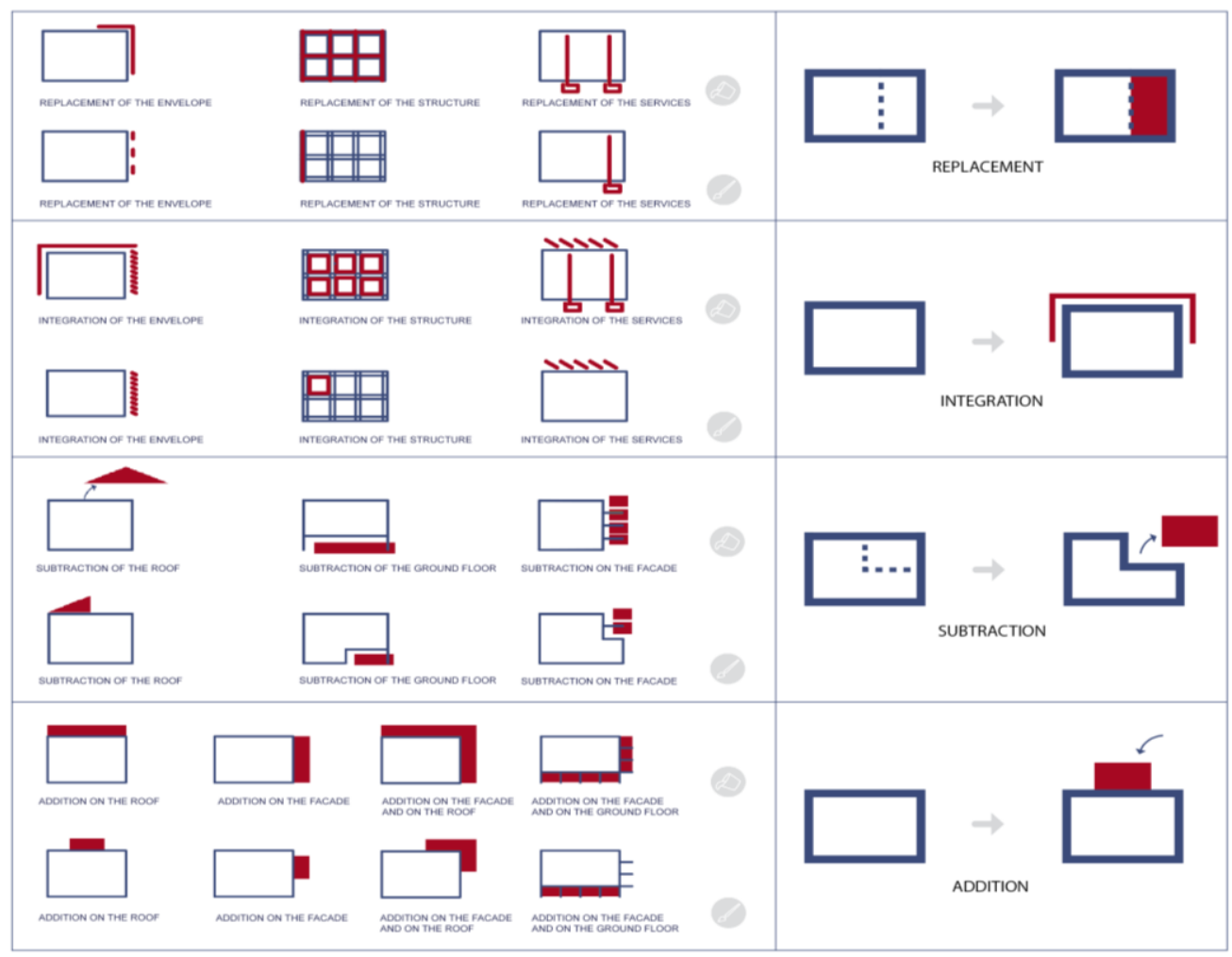

The retrofitting approach, aimed at the upgrading of the features and characteristics of buildings through the use of innovative technologies, is of particular interest for its social and environmental repercussions, and operates within the logic of a circular economy. In the case of work on post-World War II public buildings, retrofitting should be grasped as a powerful opportunity not only to remedy the physical and social deterioration found in the intermediate suburbs, but also to operate with critical capacity, combining the energy-related, seismic, and functional renewal of the buildings, in the dialectic between conservation and innovation of architecture within the logic of an economy that works in harmony with the environment.

\section{A CASE STUDY}

In order to carry out a preliminary experiment on a category of building commonly found throughout the municipal territory, we mapped out the residential areas of the city of Pisa and performed a detailed analysis of the distinctive character for each of these areas. 

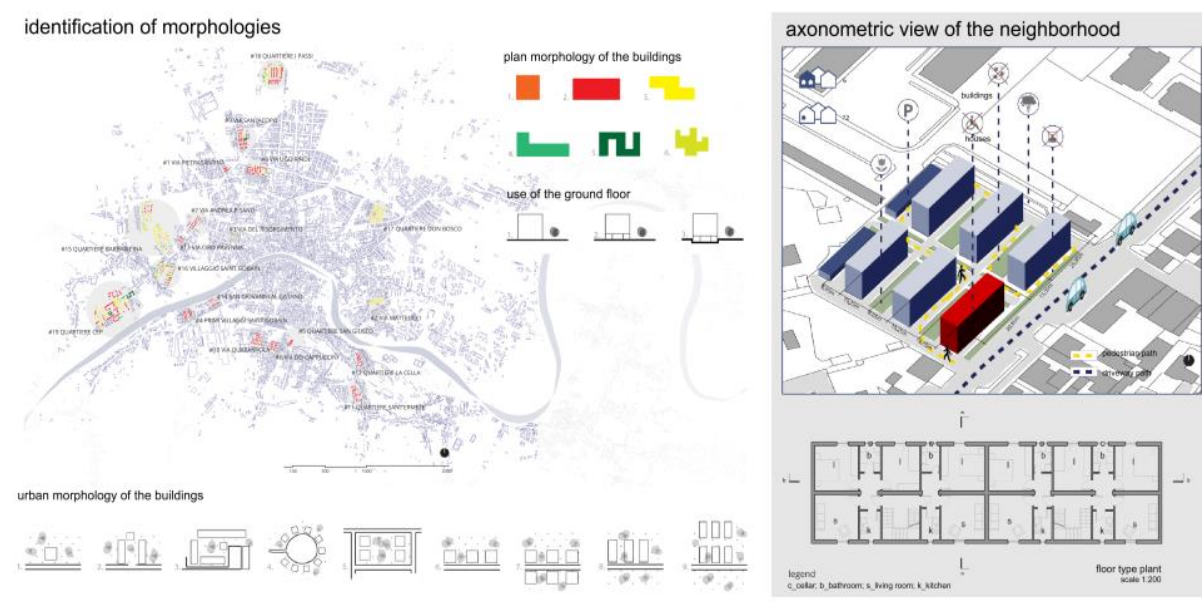

Figure 1. Preliminary study on the types of buildings and households.

The neighborhoods were classified by year of construction, size, types of buildings and property developer. The morphological layout, number of floors above ground, the construction technique, and the type of users were identified.

These considerations led to the selection for the case study being the neighborhood of Ciro Ravenna, a block consisting of six almost identical buildings three-story condominium built with load-bearing walls. See Figure 1. The examinations allowed the areas for renewal to be defined: social, technological, energy, and architectural. It was on this basis that the work schedule was planned. See Figure 2.
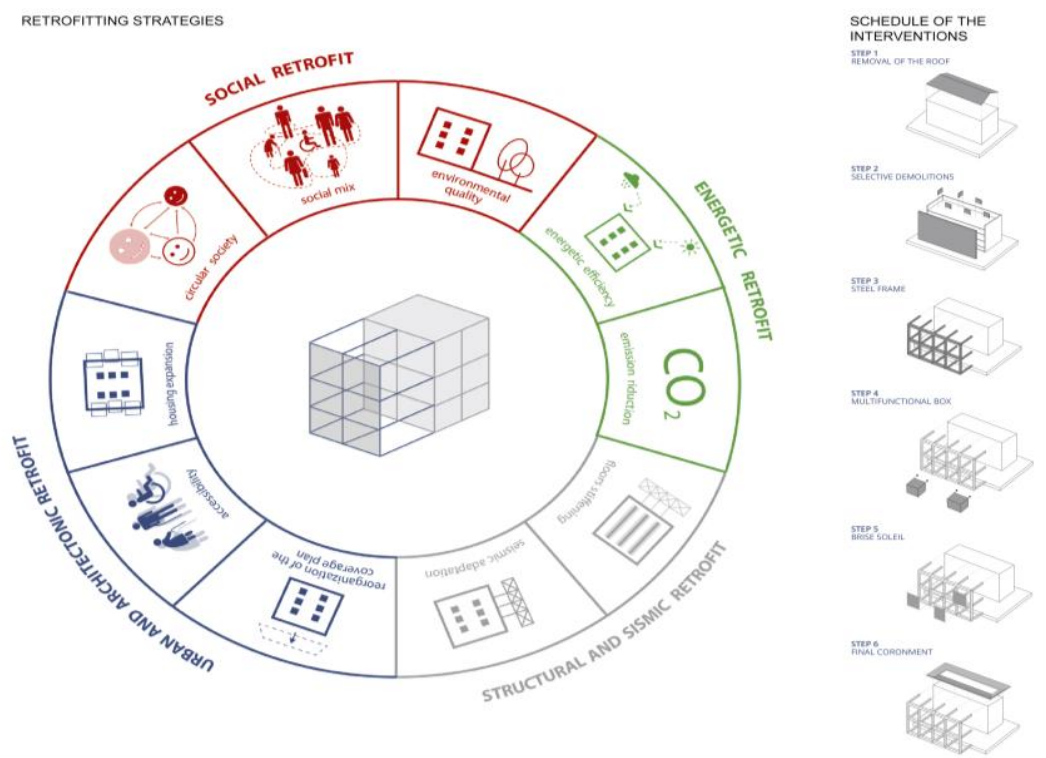

Figure 2. Retrofitting strategies and work diagrams.

As for the outdoor spaces, the entire parcel was redesigned to encourage soft mobility through the inclusion of a cycle path and rest areas. Three recreational areas have been set out in 
the green spaces that meet the needs of three different age groups: the elderly, young people, and small children. In order to create green spaces that are also educational (Stein 2010), it was decided to make one of the existing green spaces a place for gardening. A driveway was created with parking areas surrounding the block, creating a green, pedestrian center.

Since the inhabitants are at present mainly elderly people and some immigrant families (Regione Toscana 2017), the social renewal will include the integration of other types of users, such as students and young couples. There are, therefore, "4 different sizes" of residence that have been designed: XS, S, M and L. These may be combined in different configurations to meet the needs of the newer and older resident user types. Furthermore, study of the relationship between the organization of the residential layout and the furnishings made it possible to render the space more open and flexible. Particular attention was paid to vulnerable users), in order to ensure their autonomy with the provision of home automation systems. See Figure 3.
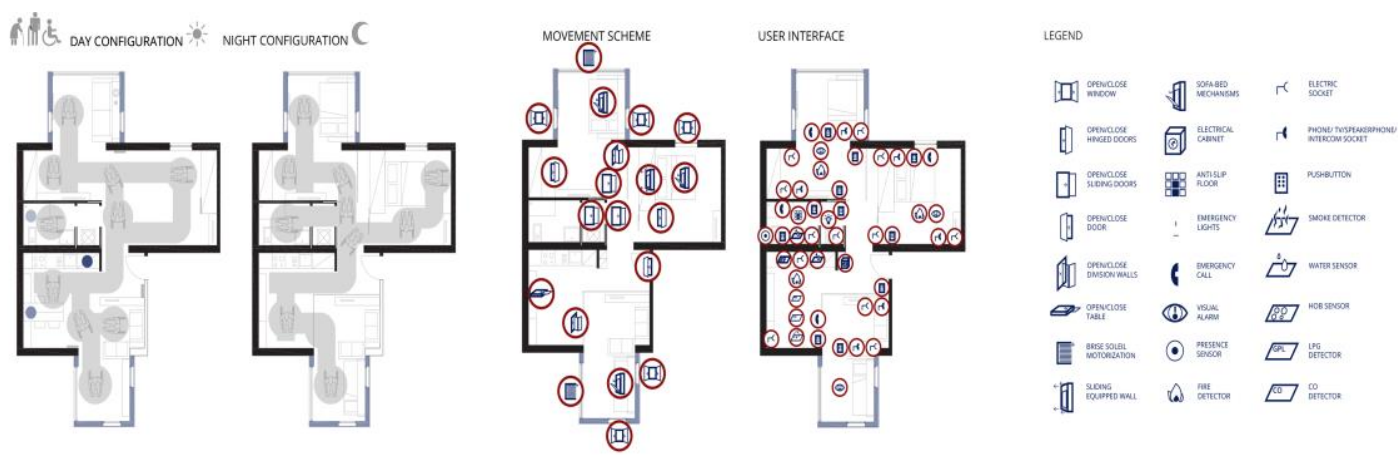

Figure 3. Day and night home automation configuration. Movement and installation interface.

The structural safety of the building has been ensured by installing a steel exoskeleton with floor and wall braces. This structural solution was enhanced from a functional and architectural point of view: in order to better integrate with the existing building (Muselli et al. 2017), a box was created, a sort of pre-fabricated wooden building prosthesis. $\mathrm{T}$ his multi-functional volumetric addition can take on different functions, depending on the different times of the day and the type of user.

The external structure, in addition to ensuring the safety of the building, serves to support the integrated solar panel and photovoltaic panel crowning system for the production of energy for use in the residences and outdoor spaces. The roof has been refurbished as a meeting place to encourage socializing and social integration for the whole building; to this end, it will include an outdoor kitchen, a relaxation area, and a central "agora" as a multi-purpose area. See Figure 4. In order to increase energy efficiency, the external facades have been integrated with insulating panels of different materials depending on the exposure (north with rock wool and south with wood fiber). These additions made it possible for the building to achieve Class A rating. Rainwater is planned to be collected in a collection and purification tank located in the basement for use by the residences or to service the outdoor spaces.

\section{CONCLUSIONS}

The technological research process in the retrofitting project described that included the addition of new technologies and new functionalities to a group of public housing buildings in order to prolong their life cycle will require further in-depth research to explore the definition of the realization costs, which are not only economic in nature, but also environmental and social, in 
order to be able to evaluate the feasibility and advantages that this approach offers. This is why the application of circular economy policies aimed at limiting waste and environmental costs, as well as the reintegration of waste materials into the production cycle play a fundamental role.
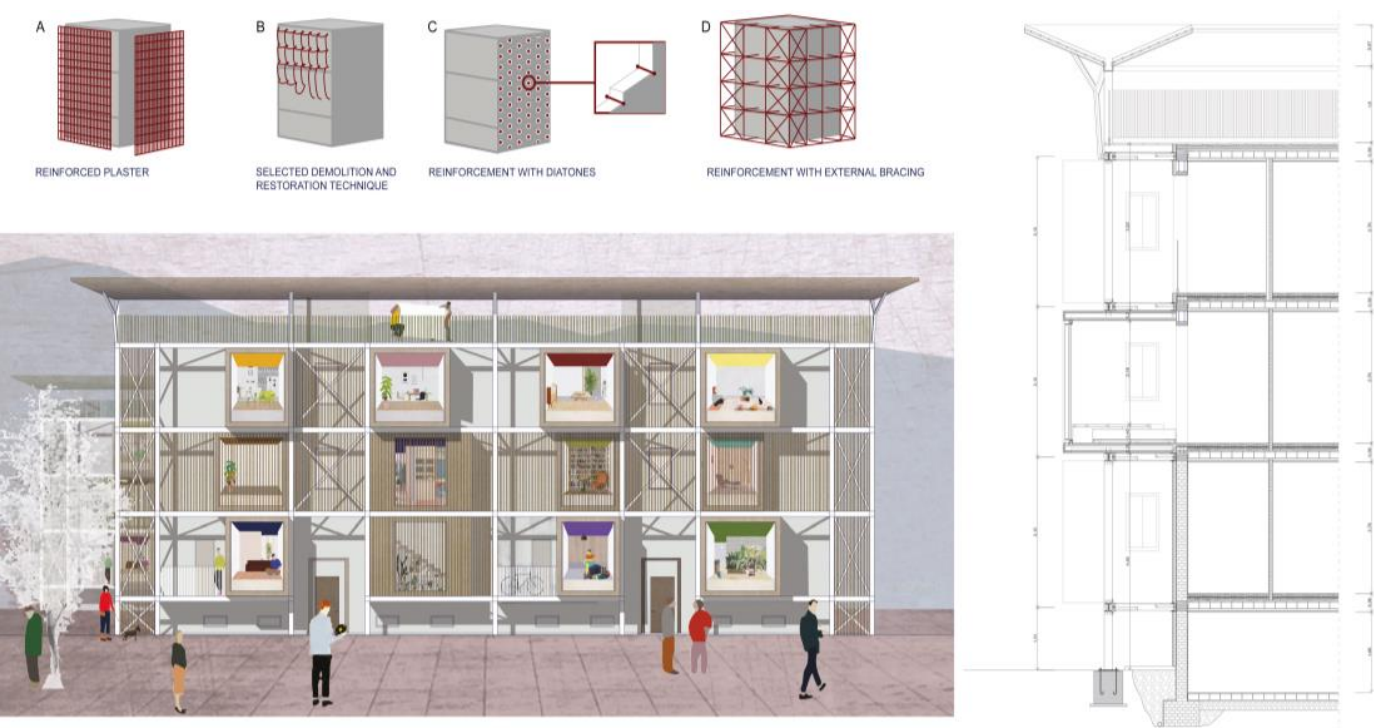

Figure 4. Structural reinforcement techniques and layout of exterior spaces.

\section{References}

Ascione, P., and Bellomo, M., Retrofit Per La Residenza. Clean Edizioni, Napoli, 2012.

Bellomo, M., and Pone, S., Il Retrofit Tecnologico Degli Edifici Esistenti: Qualità Dell'abitare, Sostenibilità Ambientale, Rilancio Economico, Techne, Firenze University Press, 1, 82-87, 2011.

Cellucci, C., and Di Sivo, M., Habitat Contemporaneo, Flessibilità Tecnologica E Spaziale, Franco Angeli Editore, Milano, 2016.

Di Sivo, M., and Angelucci, F., Il Mass Costumization Process Per L'housing Sociale, Techne, Firenze Univercity Press, 4, 132-137, 2012.

Giacchetta, A., Retrofitting Solare Di Edilizia Sociale: Un Progetto A Savona, Techne, Firenze Univercity Press, 4, 366-373, 2012.

Habraken, N. J., The Structure of the Ordinary. Form and Control in the Built Environment, The MIT Press, London, 1998.

Jacobs, J., The Death and Life of Great American Cities, Random House, New York, 1961.

Landolfo, R., Losasso, M., and Pinto, M. R., Innovazione E Sostenibilità Negli Interventi Di Riqualificazione Edilizia. Best Practice Per Il Retrofit E La Manutenzione, Alinea, Firenze, 2013.

Latouche, S., Per Un'abbondanza Frugale, Bollati Boringhieri, Torino, 2012.

Muselli, E., Tartaglia, A., and Di Pasquale, J., Typological and Technological Innovation for the Application of Hybrid Systems to Housing Construction: Between Technological Culture and Application Testing, Techne, Firenze University Press, 13, 287-294, 2017.

Regione Toscana, Abitare in Toscana - Anno 2017, Sesto Report Sulla Condizione Abitativa. Retrieved from http://www.regione.toscana.it/-/abitare-in-toscana-anno-2017-sesto-rapporto-sulla-condizioneabitativa on January 4, 2018.

Stein, C., Greenning Modernism. Preservation, Sustainability, and the Modern Movement, W.W. Norton \& Company, New York, NY, 2010.

UN-Habitat, Urbanization and Development: Emerging Futures, World City Report 2016, UN-Habitat, 2016. 